\title{
Dependence of approaches and methods of foreign language teaching on socio-economic factors
}

\author{
Korobova Ekaterina \\ Plekhanov Russian University of Economics \\ Moscow, Russia \\ ekkorobova@yandex.ru \\ Mironova Dina \\ Plekhanov Russian University of Economics \\ Moscow, Russia \\ dina_mironova@mail.ru
}

\author{
Kardovich Irina \\ Plekhanov Russian University of Economics \\ Moscow, Russia \\ ik_125212@mail.ru \\ Konysheva Marina \\ Russian University of Transport (RUT-MIIT) \\ Institute of Legal Studies \\ Moscow, Russia \\ mkonysheva@mail.ru
}

\begin{abstract}
Teaching of foreign languages has been developing for a long time. Approaches, methods and content of training change because the society sets different goals and objectives for teaching a foreign language in different historical periods and various social and economic conditions.
\end{abstract}

Keywords- foreign language, teaching, method, socioeconomic factors, competence-based approach.

\section{INTRODUCTION}

Teaching of foreign languages has a rather long history and has had several stages of development. Methods, approaches to teaching foreign languages and content of teaching programs have been changing in different historical periods as the society has set different goals and objectives for education depending on socio-economic and even political conditions and factors in each particular country or groups of countries. In this article, the authors will trace how socio-economic factors and conditions have influenced the determination of goals and objectives of teaching a foreign language in different historical periods, and what the choice of methods and content of teaching a foreign language have depended on.

\section{Methodology AND ReSEARCH MethodS}

The research was based on applying the method of historical analysis in the context of dependence of methods, approaches and content of foreign language teaching on socioeconomic conditions in different countries.

\section{RESULTS AND DISCUSSION}

Since there are different languages in the world, people have always had to look for ways to communicate with representatives of various cultures. It is obvious that even in an ancient society, in the primitive communal system with natural economy; there was a need to communicate with people from other tribes who spoke different languages. However, in an ancient society, tribes were more or less isolated from each other and communications with representatives of other tribes were rather rare and irregular. At that time it was enough to use the services of nonprofessional people who knew the languages of various tribes because they lived on the border of their habitat (very often the interpreters were captured people from a hostile tribe). These rare contacts with strangers speaking another language explain why at that time there were no special regular studies of a foreign language.

Later with the development of the human society, trade relations developed and the barter economy was formed. In that period people started to communicate with different tribes more actively, not only in war time but also in order to exchange various products. However there was no special system of teaching a foreign language, people learned the basics of oral communication during talks with other people from other places.

Later subsistence economy was changed by monetary economy and the slave system came instead of the primitive communal system. That was the period of rapid development of trade and cultural relations between different countries.

For example, in the days of Ancient Rome, it became essential to know foreign languages. The basics of the WestEuropean educational system were developed in Ancient Greece and Rome. That historical period is supposed to be the beginning of European world outlook theories [1] and linguodidactics. At that time, the main foreign languages of international communication were Greek (in the Roman era) and Latin (in the Middle Ages). Latin was taught as a foreign language for almost 15 centuries. This is the reason why teaching methodology of the Latin language was one of the first developed methods and influenced the teaching of living 
Western European languages greatly. One of the famous Roman methodologists and teachers of literature Mark Fabius Quintilian (42-118 AD) in his work "Rules of Oratory" ("On the education of the speaker") expressed an idea that the educational process directly depends on the methodology of teaching and the methods that are applied. The scientist believed that the main methods of teaching were - explanation, imitation and an exercise. [2]. These pedagogical ideas still exist in modern educational techniques and approaches.

The next period of developing methods and approaches to teaching a foreign language was in the Middle Ages. This period is characterized by gradual transfer to teaching in schools in national languages. The Latin language became not only foreign, but also dead for the European population. However, through the whole medieval period the Latin language was the language of educated people and the language of international communication in the Western World. That is why the Latin language was taught as a foreign language.

When teaching Latin, natural, grammatical-translational and mixed methods were used, which makes it possible to claim that different approaches to learning Latin in the Middle Ages were used. The natural method is close to what is called now communicative approach - the language is mastered in the real life situations, using the same methods that are used in mastering a native language. Following a natural method medieval teacher tried to create a natural language communication environment necessary for practical use of Latin.

At that period one of the first scientific methods of teaching foreign languages - a translation method was developed by a German teacher W. Ratke (1571-1635) [3]. According to this method the Latin language was taught using authentic Latin texts which were translated into the student's native language. We still can find the echoes of this method in modern approaches.

Now scientists subdivide this method into two - grammartranslation (the main attention was given to mastering grammatical structures of a foreign language and their translation into the native language) and lexical-translation (the main attention was paid not to the grammatical structure of a foreign language, but to its vocabulary). As a result, a lot of foreign words were learned and the grammatical structure was studied analytically. Nowadays this method is also called analytical-inductive. Ya.A. Comenius (1592-1670) first proposed and implemented in practice the principle of conscious learning of foreign languages. He tried to make the study of languages based on clear understanding of what was being studied. A great importance was given to the students' activity at the lesson. In contrast to V. Ratke, Ya. A. Comenius proposed analyzing specially compiled and adapted texts of educational character. The method of teaching foreign languages, which was developed by Ya.A. Comenius, is called the visual-intuitive method [4]. Today there is a great impact of this method on teaching foreign languages - educational adapted texts are widely used in modern textbooks, students' activity in the classroom is an essential principle of education at the present stage.
Nowadays there are different classifications of methods and approaches to teaching a foreign language. In general, historians identify the following groups of methods of teaching foreign languages:

- translation (grammar-translation and lexical-translation);

- direct and natural methods and their modifications;

- mixed methods;

- consciously comparative and consciously practical methods;

- activity-personal-communicative methods.

Grammar-translation and lexical-translation methods of teaching modern foreign languages existed for a long time and were the main ones for more than 200 years until the 70 s of the 19 th century. This viability of these methods is due to a number of reasons:

- the tradition of studying foreign languages for the development of students' formal-logical thinking,

- the relative flexibility of the method, the ability to adapt it to the changing social requirements of the society,

- imperceptible requirements for theoretical and practical training of foreign language teachers if they use this method of teaching.

When the feudal medieval socio-political formation was changed to capitalism, great changes in goals of learning a foreign language also took place. First of all, the policy of expanding the borders of the territories through colonization, typical of early capitalism, gave a tremendous impetus for the search for new adequate ways to teach people to communicate in various foreign languages. Colonialism started in the era of the Great Geographical Discoveries, namely in the 15th century, when the Portuguese navigator Vasco da Gama opened the way to India, and Columbus reached the shores of America. Spaniards founded the first colonies in the New World.

The colonial way of development of Britain, Spain, Portugal and other countries made it necessary to seek ways to communicate with the local population [5]. These historical factors are connected with the fact that improvement of the methodology of teaching foreign languages most rapidly developed in countries with colonies. The translation method turned out to be unacceptable in such conditions, since it is designed for educated, literate people; it takes long time and teaches only to read foreign texts. It was not suitable for illiterate aborigines and was not enough for a full-fledged foreign-language communication.

Now the results of successful teaching English in the British colonies are visible - English is spoken in all former colonies, for many it is the second state language or even the first state language. The same applies to the former Spanish and Portuguese colonies.

The British colonial system was somewhat different from the others, and, accordingly, arose such geocultural phenomenon as colonial English. One of the main differences 
was the active work with the local population, especially its educated and ruling layers. British missionaries played an active role in promoting and teaching a new language for the local population. Even in colonial times, the elite of defeated societies were educated in English universities, which quite contributed both to the spread of English in the colonies, and to association of their elites with the basics of European culture and technology.

The huge colonial possessions of Great Britain, the successful teaching of the English language to aborigines is one of the factors that at present English is the most widely spoken language, the language of international communication and is studied throughout the non-English world.

Learning English has long turned into a profitable business, and represents a significant export of services in the budgets not only of the UK, but also for Ireland, the USA, Canada, Malta and other English-speaking countries. It is taught all over the world as a second language.

Further, let us consider how the methods and approaches to teaching English as a foreign language have changed over time, depending on different requirements of the society and other socio-economic and political factors.

The authors of the first methods of teaching English as a foreign language were native speakers; they developed a kind of universal methodology that did not take into account the peculiarities of the languages of the recipient nations. All language skills were divided into four categories - reading, writing, speaking and listening; all of them were taught simultaneously. Such approach has its positive aspects, as it allows one teacher to train representatives of different nationalities in one group, which is very popular when native speakers teach in an English-speaking country or abroad.

Another advantage of such approach is considered to be the fact that the native language is absolutely excluded from the learning process and the learner is forced to communicate in a foreign language (such approach resembles "natural" method from the ancient times).

However, there are also obvious disadvantages - people speaking different languages are used in different grammatical structures, even different speech muscles work in various pronunciation models. That causes the phenomena that representatives of different language groups have their own difficulties in learning English. The speed of mastering a particular linguistic phenomenon can vary greatly, some parts of speech do not exist in another language (for example, there are no articles in the Russian language and they are very difficult to be taught to Russian speakers) and so on.

Those who have studied or taught in mixed groups with representatives of different nations probably faced some difficulty - some students are completely impossible to understand, only their compatriots understand them, since the English pronunciation is not fully assimilated without additional training by some native speakers, for example, Korean or Japanese.

That was the reason why scientists and practical teachers of other countries started developing their own methods and approaches to teaching English, taking into account the characteristics of another language and culture and the difficulties, which face different nationalities with learning a particular foreign language.

It is interesting to trace how approaches to teaching the English language were influenced by both socio-economic factors and the factors of historical development in different countries. The historical and socio-economic factors put different tasks to teaching English, the priority is given to achieving different results.

Further, let us consider how socio-economic, historical and even political factors influenced goal setting of teaching English in Russia from the $19^{\text {th }}$ to the $21^{\text {st }}$ centuries.

In the 19th century, when the international language of communication and the language of communication for uppermiddle classes was French, the goal of learning English in Russia was mainly to teach reading English literature in the original. Except some families, which at that time were called Anglophiles (for example, the family of the famous Russian writer Vladimir Nabokov), few people taught children to communicate in English. There is an interesting fact that another great Russian writer Leo Tolstoy failed when trying to communicate in English with a native speaker and switched to French, despite the fact that he was good at reading in English.

If we study the history of formation of four basic speech skills - reading, speaking, listening and writing, there are also certain trends. This or that skill is given priority at the expense of ignoring other skills [6]. As we saw in the example of prerevolutionary Russia, the main skill, which was trained, was reading.

In the first years of the Soviet Russia, the main task of the whole educational system was to teach millions of illiterate people to read and write in their native language. Another task was to teach the Russian language to national minorities [7]. New methods of teaching the English language practically were not developing at that time as the society had different tasks in education [8].

The results of the so-called "Likbez" - the state program of illiteracy liquidation in the Soviet Russia were grandiose by 1936 , about 40 million illiterates had been trained. In $1933-$ 1937, only 20,000,000 illiterates were involved in registered literacy schools. According to the census of 1939, literacy of people aged 16 to 50 was approaching $90 \%$. By the early 1940 s, the illiteracy situation in most of the Soviet regions had ceased to be catastrophic.

In the prewar years, when illiteracy was eliminated in the country, English language training was limited since more attention was paid to teaching the German language as the language of a possible enemy.

Still in some Soviet schools, English was taught, but the main principle of teaching was to get information from texts. Those texts were written by Russian authors who mostly did not have the skills and experience of foreign-language communication. Such texts were mostly ordinary primitive agitation materials translated into unnaturally sounded English. 
The main objective was not to teach English as a spoken language, but to inform Russian people about the advantages of their life - a kind of propaganda of socialist ideas.

The writing skills were worked out only by performing numerous written assignments and cannot be considered a full-fledged skill of writing in a foreign language.

Training in speaking and listening was completely excluded from the educational process, since mastering these skills would give an opportunity for a Soviet citizen to listen to foreign radio programs, communicate with foreigners, which was not welcomed by the ruling party. Therefore, the emphasis was made on learning to read and studying grammatical rules.

Because of such approach to teaching the English language, a whole generation could read English texts with a dictionary, knew the grammar rules, but could not communicate in English at all. There was a special formulation in Soviet forms - "knowing the English language with a dictionary", which sounds ridiculous for everybody, except for the people educated in the USSR.

In the 1950 s and 1960 s, the so-called "Khrushchev thaw" took place in the country. This is the name of the period in the history of the USSR, which began after the death of I.V. Stalin (1953) and continued until the early 60s. (until N.S. Khrushchev's dismissal from all leading posts). The historical term "thaw" goes back to the title of the story by IG. Ehrenburg, written in 1954-1956. Usually the "thaw" is called "Khrushchev", because it is associated with the activities of N.S. Khrushchev, who was at that time at the head of the Soviet state.

During that period the country became more open to international contacts, some international events were held in the Soviet Union - for example in 1957, the VI World Festival of Youth and Students was held in Moscow. Immediately it turned out that there was lack of people with oral communication skills in the international language. There were few really professional interpreters and guides who could easily communicate in English.

The situation was due to the methods and approaches to teaching the English language in Stalin's time. In order to improve it, the decision to set up special language schools was made.

The idea was to give the priority to teaching oral communication in a foreign language in such schools. The curriculum of teaching English in special schools was different from the traditional one. First of all English was taught from the second school year, a lot of academic hours were in the curriculum. More attention was given to developing speaking and listening skills - the first records of English texts read by native speakers were used in classes.

There were some subjects taught in English - for example English and American literature, technical translation lessons. Some experimental schools went even further and such subjects as History, Geography, Physics and Chemistry were taught in English. The results were not satisfactory, as the school-leavers were rather ignorant in all subjects taught in English.

But even there, the training was based mainly on reading and retelling old literary texts that had little to do with real live speech. Many texts were about the Communist Party of the Soviet Union and the life of ordinary Soviet people. Teachers, as a rule, had no experience of communicating with native speakers and were educated by the same Russian-speaking teachers.

When the USSR collapsed and Russia integrated into the global community in the 1990s, it became essential to train many people in the English language skills and to do it very quickly [9]. It was the period when the globalization process was developing rapidly and the knowledge of the English language became important for any person.

As the socio-economic factors of the period required a lot of bilingual specialists in all spheres of the economy, this period is characterized by the search for methods which would help to learn English quickly and easily (as is well known, such method has not been found so far).

A lot of experimental methods and approaches were tested those years. There was boom on trying new methods and approaches widely on the territory of the ex-USSR.

That period is famous for emergence and development of a whole series of new methods of teaching, known as "intensive teaching methods." Originated initially in different countries and in different years of this period, all these methods, however, are the common response of the methodology to the social order of modern society.

The new methods of teaching, which resulted from a scientific and technical explosion, reflected the modern level of knowledge of neurophysiology, psychology, in particular, the psychology of perception, the psychology of memory, the conscious and the unconscious, information theory, etc. New methods used the experience and knowledge of other related sciences, in particular linguistics, psycholinguistics, psychohygiene.

A suggestopedic direction in pedagogy appeared in connection with the attempt of the Bulgarian physician psychotherapist Georgy Lozanov to use suggestion as a means of activating the reserve mental abilities of the individual in the educational process, in particular, in teaching foreign languages.

In Russia, the followers of G. Lozanov became G.A. Kitaigorodskaya, A.A. Leontiev, N.V. Smirnova, I.Yu. Shekhter, L.Sh. Gegechkori, V.V. Petrusinsky and others, and the method itself was originally called "Lozanovsky", then "express-method" and, later, "intensive method". Lozanov's ideas were adapted and developed by the Russian teacher Kitaigorodskaya G.A. and psychologist Leontyev A.A., who became leading specialists in intensive methods of teaching foreign languages in the Soviet Union and then in Russia.

The unique methodology of intensive learning of English belongs to a group of methods considered today the most promising in terms of modern requirements for the study of foreign languages. These methods are based on the formation 
of motor speech skills and allow the person to learn a foreign language in a short time with high reliability of memorization. According to experts, such methods can reduce the training time by at least 10 times.

Nevertheless, very soon the drawbacks of this approach became obvious - only listening and speaking skills were trained at the expense of reading and writing. Intensive lessons required a lot of time, it was necessary to start practicing the language in real life situations immediately, otherwise it was quickly forgotten.

That was the time when some "miraculous" methods of teaching appeared, like learning a foreign language while sleeping, with the help of the 25th shot, the method of Ilona Davydova. (The so-called "method" was widely advertised in Russia. The main idea was based on special signals that influenced people's subconscious, but turned out to be an advertising gimmick). These "methods" obviously brought a lot of money to the authors and right holders, but did not affect the development of language skills of the population.

Many other experimental methods appeared at that time, all of them were aimed at increasing the speed of learning English. Not all these techniques have passed the test of time. Some were entertaining in the process itself, but gave no result in real-life communication with foreigners. Some of these techniques are still partly used and developed today.

The end of the $20^{\text {th }}$ and the beginning of the $21^{\text {th }}$ century are characterized by deepening the processes of globalization, information explosion, and the resulting involvement of an increasing number of specialists in various fields of science and technology, accompanied by significant growth and expansion of cultural and business contacts. As a result, the demand for specialists with language skills increased.

At the same time it turned out that our dictionaries are hopelessly outdated and do not help to understand modern texts. Only the advent of the Internet improved the situation.

It was the time when the country was flooded with English-language textbooks, written by native speakers. They were fundamentally different from the domestic textbooks of the English language, such as the famous textbook written by N.A. Bonk - boring in design, overloaded with vague explanations of how to arrange the tongue when pronouncing English sounds, with voluminous and scientific descriptions of the grammar and the domestic methodology for working with the material (strangely enough, for all its shortcomings, it was the first Soviet textbook with which one could learn not only to read, but also to speak).

English textbooks created by native speakers instantly became very popular. They represented a whole complex - a student's book, a workbook, a teacher's book, they were equipped with cassettes with authentic records of English speech.

It took quite a long time to realize that not all such textbooks are equally good, that many are written just to earn money and do not rely on serious methodological research. The most significant shortcoming of these textbooks was that they, as noted above, were created without taking into account the characteristics of representatives of different cultures and speakers of different languages. In addition, they were all general-English textbooks. Only some years later professional-English textbooks appeared.

Shortly after the invasion of foreign textbooks into the Russian educational market, there were attempts to combine the scientific Russian approach to teaching English and modern Western methods, aimed at simplifying and accelerating the learning of the language by all possible means - both visual and auditory.

The outcome of combining educational and methodical complexes written by English and American authors and developed by Russian scientists and practical teachers in order to adapt them to the peculiarities and needs of Russian learners was quite effective. This approach made it possible to combine the authenticity of texts and audio recordings with exercises and tasks aimed at concentrating on those lexical and grammatical phenomena that are difficult (abstruse) for the native speaker of the Russian language [10].

In the course of this foreign textbook adaptation to the needs and wants of Russian learners, it became obvious that the approach of English authors to introduction of new grammatical phenomena is ineffective with the Russianspeaking learners. If the English authors started with examples illustrating a new grammatical phenomenon, and then briefly explained it, for a Russian-speaking audience it is more effective first to explain the grammatical phenomenon, to show the ways of its translation into Russian, to work on simple examples, and then only apply to authentic texts.

Nevertheless, over time, this approach has also become outdated. The increasing development of the globalization processes and integration of the economies of the whole world has led to the urgent need to train specialists who do not only know a foreign language, but who are able to actively use a foreign language as a language of business and professional communication.

The new social order of a modern society is to teach a foreign language not only as a means of communication, but also to form a professionally competent polylingual and multicultural personality, ready for intercultural professional communication.

Thus, both domestic and western methods have come to recognize the need for a competence-based approach to learning a foreign language - the need not only to give the knowledge in grammar and vocabulary, but also to develop stable communication skills in a foreign language. The competence-based approach is a set of general principles for determining the goals of education, selecting the content of education, organizing the educational process, and evaluating educational outcomes. [11, 12].

Now the foreign language curriculum content includes not only lexical and grammatical units, but also those competences that will be developed in the process of learning a foreign language. At the modern stage of the society development, this approach seems to be the most reasonable, since it prepares the learner to use their language skills in real life situations. For professional higher education, the 
competence-based approach means the development of a professional foreign-language competence, that is, the ability to use a foreign language skillfully in situations of professional communication [13, 14].

To apply this approach, it was necessary to revise the methods of training used in practice. Classical Englishlanguage textbooks and methodologies of Russian teacherspractitioners were not entirely applicable $[15,16]$.

Now more and more attention is given to group project work, the case-study method, presentations, round tables, and discussions. Such forms of work solve the task of the modern time - to form foreign-language professional competence the ability and readiness of future specialists to solve communication and professional tasks, carry out search and analysis of information, work with technical literature and documentation in a foreign language in the professional field.

Students who have foreign professional competence are able to apply language knowledge in the situations of professional communication and are prepared to use a foreign language as a natural means of communication in professional activities in a multicultural environment.

\section{CONCLUSION}

The undertaken analysis leads to the conclusion that the change of methods and approaches to teaching foreign languages does not happen spontaneously. All the changes in the teaching of a foreign language are caused by a change in socio-economic and political factors and conditions, the need to fulfill the social tasks of the society, to meet the goals and objectives that society faces, and accordingly to develop certain language competencies.

\section{References}

[1] F. Engel's, F. Engel's, The old foreword to "Anti-Djuring." About the dialect, vol. 14, M.; L.: Gos. sotsial'no-ekonomicheskoe izd-vo, $1931 \mathrm{~S}$. 335-342. (in Russian).

[2] V.A. Glebovsky, Ancient pedagogical writers in biographies and samples, St. Petersburg., 1903, pp. 96-112.

[3] V.V. Ferapontov, Wolfgang Ratke and educational system in Germany in XVII century, Moscow, 2005.

[4] Ya.A. Comenius, Selected pedagogical papers. vol.2, Moscow: Pedagogika, 1982.

[5] I.L. Ekareva, "Colonialism and European Industrial Revolutions," Innovations and Investments, No. 5, pp. 58-61, 2015.

[6] M. Kaur," To Recognise, Realise and Differentiate the Learning Needs of Students," Pertanika J. Soc. Sci. \& Hum., vol. 25 (2), p. 503, Jun. 2017.

[7] History of pedagogy and education. From the birth of education in a primitive society to the end of the twentieth century: A textbook for pedagogical educational institutions. Edited by A. I. Piskunov.Moscow, 2001.

[8] M. Mayofis, "The Anxiety of Influence: Towards the Early History of Soviet Schools with the Advanced Study of Foreign Languages (late 1940s-early 1960s)," Educational Studies (Moscow), No. 2, P. 286-310, 2016.

[9] V.V. Mironov, "On the reform of Russian education Russian Education and Society", publishing house M.E. Sharpe Inc. (United States), vol, 55, No. 12, pp. 3-63, 2013.
[10] I.K. Kardovich, O.B. Dubova, E.V. Korobova, N.B. Shramkova, English for students of the professional retraining program "Translator in the sphere of professional communication" Moscow, 2016.

[11] E.V. Korobova, D.A. Mironova, "Use of the competence approach in teaching a foreign language in an economic university," Questions of Applied Linguistics, No. 14, pp. 42-49, 2014.

[12] L.A. Vovsi-Tillye, "Modular-Competence Technology," Secondary Vocational Education, No. 3, . pp. 30-31, 2011.

[13] N.A. Kalashnikova, Competence-based approach in teaching of masters. In the collection: Language and professional competencies of teachers and students in an economic institution. Materials of the XVII school of professional development of foreign language teachers of universities of economic profile, pp. 39-44, 2016.

[14] L.A. Vovsi-Tillye "Assessment of professional competence in vocational education in Great Britain," Secondary vocational education, No. 4. pp. 47-48, 2003.

[15] A. Dolzhikova, V. Kurilenko, Yu. Biryukova, "Integrative teaching model of reading as a component of translator's professional activity ", "3rd international multidisciplinary scientific conference on social sciences \& arts SGEM 2016: conference proceedings", Book 3, vol. 1, pp. 553-562, 2016.

[16] E. Malushko, A. Novozhilova, Ye. Shovgenina, S. Korolkova, A. Shovgenin, "Developing professional competence of a translator: information retrieval and information technology constituents","3nd international multidisciplinary scientific conference on social sciences \& arts SGEM 2016: conference proceedings", Book 1, vol. 1, pp. 669-676, 2016. 